\title{
BIBLIOTECAS PÚBLICAS: Proposta para um Serviço de Informação à Comunidade
}

\author{
Iara Maria Felix Silva \\ Especialista em Gestão e Tecnologia da Informação \\ Graduada em Biblioteconomia \\ Universidade Federal de Pernambuco \\ iarafelixs@gmail.com
}

\section{Resumo}

Proposta de criação de um Serviço de Informação à Comunidade (SIC) na Biblioteca Pública do Estado de Pernambuco (BPE). Destacam-se as funções básicas da biblioteca pública ao longo do tempo e a sua evolução decorrente de mudanças sociais, políticas, educacionais e tecnológicas. Enfocam-se do SIC/BPE: necessidades, finalidade, objetivos e aspectos administrativos (subordinação, horário de funcionamento, equipe, localização, recursos materiais e relações com os outros setores da BPE). Apontam-se os produtos de informação que gerariam valor agregado. Na medida em que haja recursos, tem o intuito de contribuir para implantação do serviço de informação à comunidade em outras bibliotecas públicas no Brasil.

\section{Palavras-chave}

Biblioteca Pública. Serviço de informação à comunidade. Informação utilitária.

\section{INTRODUÇÃO}

O avanço da tecnologia tem provado que é possível inovar, convertendo o antigo no novo. Já se foi o tempo em que a biblioteca pública tinha apenas a função de "guardiã da memória". Ela ultrapassou tal limite quando, ao longo de sua história, foi conquistando espaços através de diversificadas ações (culturais, educacionais e de inclusão digital) para atingir seu objetivo de preservar e difundir a informação e, principalmente, fortalecer a cultura local.

Marcada por diferentes categorias, a biblioteca pressupõe algo mais que um espaço destinado à produção intelectual: representa um instrumento vigoroso capaz de favorecer, ressaltar, silenciar, ou ocultar a preservação e/ou difusão de informações que podem influir ou transformar, direta ou indiretamente, as inter-relações sociais. (VERRI, 1996, p. 32).

Com dificuldade, é possível se observar que a sociedade, mesmo com características diferenciadas, desperta em diversos níveis para a importância da biblioteca pública. Valorização que pode ser atribuída ao fato de a biblioteca oferecer serviços que suprem as necessidades de informação, educação e lazer dos que a procuram. Assim, a população passa a vê-la como uma instituição voltada para o desenvolvimento do cidadão, colaboradora para melhoria de sua qualidade de vida, se encontrar na biblioteca pública um ambiente que lhe oferece as informações necessárias ao seu progresso. Essas informações estão atreladas a um serviço que, nos dias de hoje, tem uma considerável demanda, tornando-se cada vez mais visível a importância de sua inclusão na roti- 
na de uma biblioteca pública: o Serviço de Informação à Comunidade (SIC).

A Biblioteca Pública do Estado de Pernambuco (BPE) exerce as funções de promotora da leitura, agente e centro de informação, cultura, lazer e desenvolvimento da cidadania. Disponibiliza materiais bibliográficos e especiais à clientela; dispõe na Praça da Informação de uma infraestrutura que possibilita à comunidade usuária o acesso à Internet. $O$ interesse por esse tema surgiu de fatos observados ao fazer parte do grupo de rodízio aos sábados, no atendimento ao público na Praça da Informação ou na Seção de Assistência ao Usuário (Referência) da Biblioteca. Percebeu-se que, às vezes, não se dispunha nas coleções de fontes de informação e nem de pessoal habilitado para responder algumas das indagações relacionadas à solução de problemas rotineiros dos cidadãos.

O uso da tecnologia da informação tem contribuído para o desenvolvimento dos serviços oferecidos pela BPE, e é diante desse cenário de novas perspectivas que o SIC se insere, tendo como objetivo oferecer informações úteis à comunidade. Supõe-se que a oferta de um serviço desse porte destinado a atender às necessidades de informação relativas à melhoria da qualidade de vida, à solução de problemas e à concretização de anseios pessoais em bibliotecas públicas seja de fundamental importância para reduzir as barreiras que separam os grupos sociais quanto ao acesso à informação.

Este estudo propõe a criação de um SIC na BPE. Pontua alguns relatos de experiências no Brasil. Enfoca-se, resumidamente, a evolução do conceito de biblioteca pública. Apresenta-se uma breve explanação sobre a biblioteca pública no Brasil e a BPE. Do SIC, abordam-se sua necessidade na BPE, subordinação administrativa, horário de atendimento, localização, equipe, recursos materiais, finalidade, objetivos, áreas das informações e relacionamentos com outros setores. Destacam-se os produtos de informação a serem gerados como valor agregado a esse serviço.

\section{REVISÃO DA LITERATURA}

A biblioteca pública tem um importante papel frente à sociedade, devendo promover o livre acesso à informação. Com efeito,

\begin{abstract}
Dentre todos os tipos de bibliotecas, é a única que possui realmente características de uma instituição social, tanto pela amplitude de seu campo de ação quanto pela diversificação de seus usuários. (SUAIDEN, 1995, p. 20 apud BERNARDINO; SUAIDEN, 2011, p. 38).
\end{abstract}

Essa afirmação corrobora para a evidência de que as bibliotecas públicas estão cada vez mais inseridas no contexto da sociedade, participando de ações sociais, e consequentemente, agregando valores à sua função social. Figueiredo (1989), há mais de 20 anos, advogava pela implantação de serviços de informação para a comunidade.

A informação utilitária forma pontes com o público a partir de suas necessidades:

\footnotetext{
Ela busca não apenas atender a eventuais demandas, mas estar presente na vida da coletividade, ligando os diversos segmentos populares às esferas de seus interesses e necessidades. (MILANESI, 1990, p. 76).
}

O Manifesto da International Federation of Library Associations (IFLA) e da Organização das Nações Unidas para a Educação, a Ciência e a Cultura (UNESCO) sobre Bibliotecas Públicas de 1994 (Anexo) ressalta seu papel de prestadora de serviços à comunidade, ao listar 12 missões-chave relacionadas com a informação, a alfabetização, a educação e a cultura. Sendo uma delas:

\section{[...] assegurar o acesso dos cidadãos a todos os tipos de informação da co- munidade local; proporcionar serviços de informação adequados às empresas locais, associações e grupos de interes- se [...] (MANIFESTO..., 1994, p. 2).}

Almeida Júnior (1997), ao abordar bibliotecas públicas e bibliotecas alternativas, destaca o serviço referencial e de informação e afirma que esse último serviço é uma proposta alternativa para a biblioteca pública e 
recebe denominações variadas (Centro Referencial, Centro de Informação para a Comunidade, Serviço de Informação para a Comunidade), destacando que as propostas de trabalho, atividades e estrutura são quase idênticas à do Serviço Referencial de Informação. Essa quase similitude se fazia presente nos Estados Unidos e em alguns países da Europa, em contraposição à realidade biblioteconômica brasileira.

A implantação de um serviço de informação à comunidade em bibliotecas públicas colabora para a redução das barreiras que separam os grupos quanto ao acesso à informação. É um valioso instrumento para atender eficientemente seus usuários, oferecendo orientação e assistência necessárias para solucionar problemas da vida diária, como destaca Zaher (2000, p. 7), na época, Diretora da Fundação Biblioteca Nacional:

Ao exercer seu papel social e informativo, a biblioteca pública brasileira contribui de forma eficaz para minimizar um dos mais sérios problemas da sociedade atual, ou seja, a desigualdade entre os que têm acesso à informação e os que são desprovidos dela.

De acordo com Correia (2005, p. 13), a biblioteca pública:

\begin{abstract}
Emerge como um espaço de cidadania, na medida em que configura um espaço profundamente democrático de fruição da cultura, aberta a todos, independentemente da condição social e do grupo etário. [...] ao mesmo tempo que propicia a socialização em torno de práticas culturais mais próximas da cultura erudita, a biblioteca pública pode ainda desempenhar um papel importante no desenvolvimento das competências indispensáveis à plena participação de todos os cidadãos na sociedade.
\end{abstract}

A análise da comunidade em todos os aspectos (culturais, econômicos, sociais e políticos) tem como fim o conhecimento da procura e da oferta de serviços existentes no entorno da biblioteca pública, bem como a identificação das necessidades dos cidadãos em relação à oferta bibliotecária. O compromisso do profissional de biblioteconomia, como agente social de mudança, requer conhecer a realidade da população local. Portanto, é necessário um planejamento bem estruturado para que a implantação de um serviço venha a atender às reais necessidades da comunidade.

Um estudo realizado por Isabel D. Pereira da Costa, da Biblioteca Municipal de Ponte de Lima em Portugal, durante o Mestrado de Ciências Documentais, pela Universidade de Évora, visa identificar que tipo de serviço de informação à comunidade é prestado pelas bibliotecas públicas portuguesas. Esclarece que o desenvolvimento em qualidade e quantidade dos serviços prestados pelas bibliotecas portuguesas ocorreu devido à criação do programa da Rede Nacional de Bibliotecas Públicas em Portugal, em 1987, e que em algumas ocasiões

Foram feitas referências à necessidade das bibliotecas prestarem ou criarem um serviço de informação à comunidade, seguindo um pouco o modelo inglês dos Community Information Service. (COSTA, 2004, p. 1).

No Brasil, existem trabalhos bemsucedidos desse tipo de serviço, entre eles o criado na Biblioteca Pública Municipal de Londrina (PR), o Projeto de Serviços e Informações Utilitárias (PSIU), e a experiência em Santa Rita (PB), realizada pelo curso de Mestrado de Biblioteconomia da Universidade Federal da Paraíba (UFPB), com área de concentração em bibliotecas públicas. O primeiro trabalho foi implantado em 1994 com a proposta de centralizar e oferecer informações através de uma base de dados sobre assuntos como: turismo, cultura, utilidade pública, serviços da cidade de Londrina. Gléria e Alves Filho (2000, p. 127) informam que a ideia do PSIU

[...] surgiu após constatação da ausência de um serviço que concentrasse informações sobre utilidade pública, cultura, lazer e serviços de forma rápida e dinâmica para atender à comunidade londrinense e visitantes ou turistas.

E que diante dessa realidade,

A Biblioteca Pública Municipal de Londrina reuniu informações sobre a cidade para compor uma base de da- 
dos que garantisse um atendimento rápido e eficaz ao público visando a sanar a carência de informações. (GLÉRIA; ALVES FILHO, 2000, p. 127).

No município de Santa Rita, o intuito da UFPB foi transformar a Biblioteca Pública Otávio Amorim em um centro de informação utilitária, devido à "inexistência de qualquer trabalho deste gênero junto à população, e por oferecer condições adequadas a essa atividade", o que gerou um relatório dos resultados referentes aos dados coletados para análise e avaliação pelos pesquisadores e pesquisados que serviram para a elaboração de um plano de ação. (COSTA, 1984, p. 181).

Há outros relatos no Brasil e no exterior que reforçam a importância da implantação de um serviço que ofereça à comunidade o acesso a informações que possibilitem a resolução de problemas do cotidiano e disponibilize fontes sobre educação, cultura, saúde, cidadania e lazer.

\section{BIBLIOTECA PÚBLICA}

A biblioteca pública não foi, não é ou nem sempre será a mesma, pois ao longo de sua existência, vem acompanhando os avanços sociais, políticos, educacionais e tecnológicos ocorridos no Brasil e no mundo, sendo modificada por eles. É, essencialmente, uma instituição de prestação de serviços, tem como base a igualdade de acesso para todos, independentemente de idade, raça, sexo, religião, nacionalidade, língua ou condição social.

\subsection{Evolução do conceito de biblioteca pública}

Desde o final do século XIX até metade do século XX, houve uma divisão de interesses entre bibliotecas públicas e processos documentários, com maior ênfase nos Estados Unidos e na Europa. (ORTEGA, 2004). A biblioteca pública foi criada na Inglaterra como consequência da Revolução Industrial, e, desde o final do século XIX, vem passando por profundas mudanças em seu conceito.

O Quadro 1, elaborado pela autora deste estudo, mostra de forma sintética os fatos que se destacaram para ocorrência dessas mudanças.

Quadro 1 - Evolução da biblioteca pública

\begin{tabular}{|c|c|}
\hline FATOS & DESCRIÇÃO \\
\hline Revolução Industrial (1850) & $\begin{array}{l}\text { O conceito inicial vinculado à classe trabalhadora e às funções } \\
\text { educativas e moralizantes. }\end{array}$ \\
\hline $\begin{array}{l}\text { Crise econômica dos anos } 30 \text { e a } 2^{a} \text { Guerra } \\
\text { Mundial (1930-1945) }\end{array}$ & $\begin{array}{l}\text { Conceito como instrumento para a paz e a democracia, identi- } \\
\text { fica-se com a classe média e a população estudantil. }\end{array}$ \\
\hline UNESCO - 1949: $1^{\text {a }}$ versão do Manifesto & $\begin{array}{l}\text { Destaca a função da biblioteca pública em relação ao ensino e a } \\
\text { caracteriza como centro de educação popular. }\end{array}$ \\
\hline $\begin{array}{l}\text { Década de } 50 \text { (1950) - Questionamento por } \\
\text { parte da classe bibliotecária }\end{array}$ & $\begin{array}{l}\text { O papel da biblioteca pública e sua identificação com os valo- } \\
\text { res da classe média e a cultura de elite. Destaque para os Esta- } \\
\text { dos Unidos e Inglaterra. }\end{array}$ \\
\hline $\begin{array}{l}\text { Décadas de } 60 \text { e } 70 \text { (1960-1970) - Questiona- } \\
\text { mentos por parte dos Movimentos Culturais }\end{array}$ & $\begin{array}{l}\text { Função de caráter mais social: voltada para as classes mais } \\
\text { desfavorecidas da sociedade. }\end{array}$ \\
\hline UNESCO - 1972: $2^{\mathrm{a}}$ versão do Manifesto & Sintetiza as funções em: educação, cultura, lazer e informação. \\
\hline $\begin{array}{l}\text { Década de } 80 \text { (1980) - Desenvolvimento da } \\
\text { sociedade de Informação e Comunicação }\end{array}$ & $\begin{array}{l}\text { Uso generalizado dos computadores e das novas tecnologias de } \\
\text { comunicação nas bibliotecas; surgem as redes de bibliotecas. }\end{array}$ \\
\hline $\begin{array}{l}\text { Década de } 90 \text { (1990) - Sociedade da Informa- } \\
\text { ção/Conhecimento }\end{array}$ & $\begin{array}{l}\text { Revolução digital: necessidade de adaptação, por parte da soci- } \\
\text { edade, às crescentes mudanças. }\end{array}$ \\
\hline UNESCO - 1994: $3^{\text {a }}$ versão do Manifesto & $\begin{array}{l}\text { Compromisso da biblioteca pública com a democratização do } \\
\text { acesso às novas tecnologias de informação. }\end{array}$ \\
\hline $\begin{array}{l}\text { O Livro Verde - } 1997 \text { - Combate à info- } \\
\text { exclusão }\end{array}$ & $\begin{array}{l}\text { Entre as medidas indispensáveis para combater a info-exclusão, } \\
\text { destaca-se o acesso à informação nas bibliotecas públicas. }\end{array}$ \\
\hline Século 21 - Tecnologia/Indivíduo/Sujeito & $\begin{array}{l}\text { Conceito de sociedade do conhecimento com foco no indiví- } \\
\text { duo. }\end{array}$ \\
\hline
\end{tabular}


A ideia de um serviço de informação à comunidade teve início na Inglaterra, onde funcionava um escritório para aconselhamento dos cidadãos - British Citizens Advice Burean - praticado por voluntários, "essa idéia foi transplantada para os Estados Unidos, inspirando os bibliotecários a criarem estes serviços dentro das bibliotecas públicas". (FIGUEIREDO, 1985 , p. 9). Constituiu um novo enfoque dado pelos bibliotecários, adequado às necessidades da sociedade, sem descuidar dos grupos especializados. Em 1976, foi criada a Biblioteca Pública de Caracas na Venezuela, nascendo, assim, o serviço de informação à comunidade em biblioteca. A finalidade desse serviço é fornecer informação útil e relevante para o cotidiano das pessoas.

De acordo com a terceira versão do Manifesto da IFLA/UNESCO (1994), estão inseridas dentre as missões básicas da biblioteca pública:

a) possibilitar o acesso a todas as formas de expressão cultural das artes do espetáculo;

b) assegurar o acesso dos cidadãos a todos os tipos de informação da comunidade local; e

c) proporcionar serviços de informação adequados às empresas locais, associações e grupos de interesse.

\subsection{Biblioteca pública no Brasil}

Em 1811, por iniciativa dos cidadãos, foi criada na cidade de Salvador, Bahia, a primeira biblioteca pública do Brasil, com a função de apoio à educação. As bibliotecas instaladas no período de 1890 a 1930 foram resultado de obstinados esforços isolados de alguns elementos para levar avante a ideia transplantada de biblioteca pública. De acordo com dados do Sistema Nacional de Bibliotecas Públicas (SNBP), até o mês de abril de 2015, o Brasil possuía 6.102 bibliotecas públicas municipais, sendo 503 na Região Norte, 1847 na Região Nordeste, 501 no Centro-Oeste, 1958 no Sudeste e 1293 na Região Sul (SISTEMA NACIONAL DE BIBLIOTECAS
PÚBLICAS, 2015). Com o passar dos anos, a biblioteca pública incorporou novas ações à sua função, somando esforços para erradicar o analfabetismo e promover a inserção social dos indivíduos através da leitura - que é a condição essencial para que o indivíduo tenha acesso à informação - e dos meios de comunicação de massa.

Toda biblioteca pública brasileira deve estar registrada no SNBP, instituído na Fundação Biblioteca Nacional (FBN) pelo Decreto Presidencial n. 520, de 13 de maio de 1992, tendo como objetivo principal o fortalecimento das bibliotecas públicas no país. O Sistema tem a função de coordenar e promover ações junto aos Sistemas Estaduais de Bibliotecas Públicas, que funcionam, em cada estado da Federação, articulando-se com as bibliotecas públicas municipais e comunitárias. Cadastrada, a biblioteca passará a usufruir dos programas desenvolvidos pelo Sistema Nacional. (BIBLIOTECA..., 2000).

\subsection{Biblioteca Pública do Estado de Pernambuco (BPE)}

A Lei Provincial $n^{\circ}$ 293, de 5 de maio de 1852, criou a primeira Biblioteca Pública em Pernambuco, denominada Biblioteca Pública Provincial, funcionando anexa ao Liceu, situado onde hoje existe a Av. Dantas Barreto, Recife-PE, obrigando as tipografias a remeterem um exemplar de todas as publicações e a incorporação à Biblioteca da livraria existente no Liceu. O seu primeiro regulamento foi aprovado e publicado em 1874. (VERRI, 1996).

Em 1890, com a Proclamação da República, passou a chamar-se Biblioteca Pública do Estado de Pernambuco, funcionando, posteriormente, em diversos locais. Em 1971, no governo de Nilo Coelho, foi transferida, definitivamente, para sede própria, em prédio com instalações específicas, dentro das normas da moderna arquitetura, próximo ao Parque Treze de Maio, onde até a presente data se localiza. Nessa ocasião, passou a denominar-se Biblioteca Pública Estadual Presidente Castello Branco. Em $1^{\circ}$ de março de 2002, 
através do Decreto $\mathrm{n}^{\circ}$ 24.075, voltou a chamar-se Biblioteca Pública do Estado de Pernambuco (BPE). (PERNAMBUCO, 2018).

A BPE está em constante desenvolvimento como uma prestadora de serviços. Tem a missão de disponibilizar, de forma democrática, toda memória que constitui seu acervo, além de fomentar o gosto pela leitura através de ações culturais, exercendo a importante função de órgão difusor do conhecimento e impulsionador dos caminhos da modernidade e da cidadania.

Ocupa uma área de $5.000 \mathrm{~m}^{2}$ e oferece aos usuários um acervo diversificado e amplo, constituído por mais de 270 mil volumes de livros, distribuídos em 15 coleções: Referência, Didática de Referência, Infantojuvenil, Obras Raras, Coleção Pernambucana, Manuscritos, Iconografia, Mapoteca, Braille, Periódicos, Circulante, Acervo A, Acervo B, Caixa-Estante e Praça da Informação. Possui mais de 370 mil volumes de periódicos entre nacionais e estrangeiros, mapas, manuscritos, iconografia e folhetos, compreendidos em coleções diversas. O seu atendimento se estende a toda a comunidade pernambucana. Coordena o Sistema de Bibliotecas Públicas de Pernambuco e está estruturada em três unidades: Unidade de Atendimento ao Usuário e Coleções Especiais, Unidade de Processos Técnicos e a Unidade de Assistência às Bibliotecas Públicas Municipais. (PERNAMBUCO, 2018).

A Unidade de Atendimento ao Usuário e Coleções Especiais é responsável pela prestação dos serviços à clientela. Disponibiliza as diversas fontes de informação existentes na Biblioteca, tradicionais e online. Destaca-se pela singularidade o Registro de Direito Autoral, que atende ao Estado de Pernambuco e estados vizinhos. Desenvolve ações culturais. É composta pelas seguintes Seções: Assistência ao Usuário (Referência), Infantojuvenil, Circulante, Periódicos, Braille, Ação Cultural e Multimídia, Obras Raras e Coleção Pernambucana. Oferece, também, um espaço denominado Praça da
Informação, que possibilita ao usuário o uso de computadores e o acesso à Internet.

A Unidade de Processos Técnicos coordena, realiza e controla as atividades de seleção, aquisição, registro, preparação técnica e física para uso, desbaste, inventário e avaliação dos acervos bibliográfico e especial. Composta pela Seção de Seleção e Aquisição e a de Representação Descritiva e Temática. Oferece também o serviço de Catalogação na Fonte. É a recebedora do depósito legal de três exemplares de obras editadas no Estado, no país e no exterior, que sejam provenientes de autores pernambucanos ou radicados no Estado ou que versem sobre a história de Pernambuco, produzidas por qualquer processo de impressão ou suporte, obrigatoriamente, conforme estabelece a Lei $\mathrm{n}^{\circ} 12.435$, de 6 de outubro de 2003, que dispõe sobre a remessa, o depósito legal e a guarda de obras culturais à BPE, com objetivo principal de assegurar a coleta, a guarda e a difusão da produção intelectual pernambucana, visando à preservação e formação da coleção memória do Estado de Pernambuco, a Coleção Pernambucana. (PERNAMBUCO, 2018).

A Unidade de Assistência às Bibliotecas Públicas Municipais tem como missão principal a implantação e manutenção de bibliotecas públicas nos municípios do Estado, desenvolve atividades visando a incentivar a educação, pesquisa e cultura. Dentre suas várias ações, destaca-se o Serviço de Extensão "Quem se informa está mais forte" (Caixa-estante), que tem o objetivo de fomentar o interesse pela leitura através da oferta de obras a comunidades não assistidas por serviços de biblioteca, localizadas em creches, hospitais, presídios, dentre outras instituições sociais.

\section{SERVIÇO DE INFORMAÇÃO À COMUNIDADE (SIC)}

Propõe-se a implantação do SIC para oferta de informações que auxiliem na resolução de problemas da vida diária, melhoria da qualidade de vida, realização de anseios pessoais e exercício da cidadania, 
subordinado à Unidade de Atendimento ao Usuário e Coleções Especiais, desenvolvendo parcerias com as seções de Assistência ao Usuário (Referência), Infantojuvenil, Periódicos, Braille, Ação Cultural e Multimídia e a Praça da Informação, todas da citada Unidade.

Constituiria uma das atividades decorrentes da atitude proativa desenvolvida pela BPE. Tendo função informativa, educativa, cultural e de entretenimento.

Seriam seus objetivos específicos:

a) criar e manter arquivos de informação sobre atividades culturais, de lazer e educativas oferecidas gratuitamente e a preço módico por instituições públicas e privadas;

b) elaborar e manter cadastro de entidades públicas e privadas que atuam nas áreas de educação, saúde, cidadania, cultura e lazer, localizadas em Pernambuco;

c) divulgar atividades informativas, educativas, culturais, de diversão e incentivar a participação da comunidade usuária da $\mathrm{BPE}$;

d) implantar e manter no site da BPE
páginas para divulgar atividades,
principalmente as gratuitas e a preço
módico;

e) participar do combate à exclusão social e à info-exclusão;

f) fazer levantamento e divulgação permanentes de oportunidades de trabalho, estudo e lazer, concursos etc.;

g) intermediar o uso e a participação da clientela da BPE em entidades sociais, educativas, culturais, de exercício ativo da cidadania e nas políticas públicas; e h) desenvolver parcerias com órgãos públicos e privados para conhecer e divulgar o que realizam nas áreas de interesse do SIC.

Sua finalidade: atender à clientela da BPE, utilizando as fontes de informação disponíveis (acervo da BPE, sites e arquivos de informação) e através de outras instituições, servindo de ponte entre $\mathrm{o}$ usuário e a informação.

O ideal é que esse serviço estivesse localizado na entrada da Biblioteca, próximo à Seção de Assistência ao Usuário (Referência), e fosse visualizado pelo usuário logo ao adentrar no recinto.

Consideram-se como recursos humanos necessários para a execução das atividades: 2 (dois) bibliotecários e 2 (dois) assistentes administrativos. Quanto aos recursos materiais: 1 (um) balcão de atendimento, 2 (dois) microcomputadores, 1 (um) quadro (para aposição de avisos, mensagens e panfletos informativos) e uma estante.

$\mathrm{O}$ atendimento à clientela dar-se-ia de segunda à sexta-feira, das 8 às 21 horas. Conforme o volume da demanda, a equipe, os mobiliários e os equipamentos seriam ampliados, bem como se passaria a atender aos sábados.

A Figura 1 apresenta a imprescindível interação que precisa existir entre o SIC, a Seção de Assistência ao Usuário (Referência) e a Praça da Informação. O Serviço seria uma espécie de filtro para estes dois últimos setores da BPE. Complementaria as ações deles.

Figura 1 - Trinômio da informação

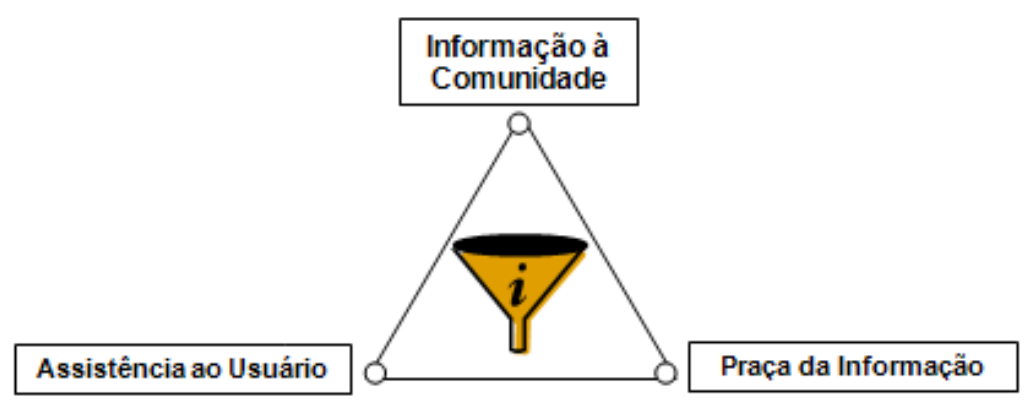

Fonte: elaborado pela Autora (2009). 
Neste contexto, fica evidente a importância de sua implantação na BPE para proporcionar à comunidade um novo serviço de informação.

As necessidades e os anseios inerentes ao ser humano os levam a buscar respostas que venham auxiliar ou solucionar suas indagações. Ao comentar a oferta de serviços de informação pela biblioteca pública, Duckworth (1991, p. 212 apud ABATH et al., 1996, p. 46) destaca sua postura pouco democrática:

Geralmente os serviços oferecidos são realizados sem nenhuma consulta à comunidade a qual está vinculada. Esses serviços são de certa forma impostos pela biblioteca no momento que julgam que os serviços que oferecem, é o que responde à necessidade de informação da comunidade. Com esta atitude os serviços prestados ficam distantes da realidade.

Estudos para identificar o perfil da clientela e as informações que lhe seriam úteis e detectar o que oferecem o serviço de informação de outras instituições localizadas no entorno da biblioteca pública - para evitar duplicação de recursos e esforços constituem etapas essenciais para assegurar o bom desempenho, qualidade e êxito do SIC.

O papel social da biblioteca pública de contribuir para o desenvolvimento sociocultural da comunidade em que está inserida, principalmente seu compromisso em tornar acessível às informações que os indivíduos das classes mais desfavorecidas necessitam no seu dia a dia, está claramente perceptível no conceito de centros de informação de Usherwood (1992 apud ABATH et al., 1996, p. 46):

\footnotetext{
Aqueles que auxiliam indivíduos e grupos na solução de problemas diários e na participação do processo democrático. Os serviços concentramse nas necessidades daqueles que não têm rápido acesso a outras fontes de assistência, e nos mais importantes problemas que os mesmos enfrentam como os relacionados com moradia, emprego e direitos.
}

Figueiredo (1985, p. 15) afirma que, além da informação direta (fatos, endereços, telefones etc.), poderiam ser prestados outros serviços de informação à comunidade, tais como:

a) aconselhamento - sobre escolha de cursos, livros, etc.;

b) referral prático - colocar usuários em contato com outros indivíduos que estejam em outro local (biblioteca, etc.) para explicação de alguma dúvida; e

c) mediação - algumas vezes, é preciso interceder, quando é percebido que a explicação não está sendo assimilada pelo usuário ou vice-versa.

A proposta de criação do SIC tem a intenção de dinamizar os serviços oferecidos pela BPE, servindo como um elo da comunicação, um facilitador no desempenho das atividades desenvolvidas pelos funcionários e agentes na transmissão da informação. Seria um centro de intermediação das necessidades, anseios e indagações da clientela que busca informação para resolver seus problemas e contribuir para o fortalecimento da identidade cultural da comunidade.

Figura 2 - Esboço do cenário do SIC

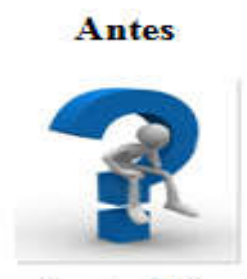

(entrada)
Durante

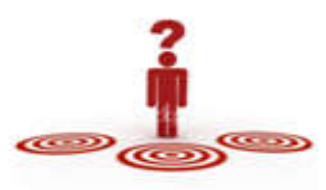

(intermediação)

\section{Depois}

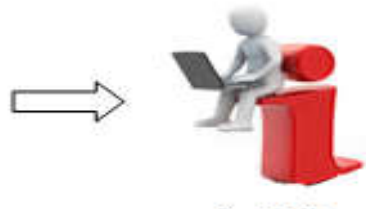

(saída)

Fonte: elaborado pela Autora (2009). 
Para uma melhor compreensão da dimensão em que o SIC poderá alcançar, em termos de qualidade de serviço, visualize-se um shopping, não pensando na transação comercial, sim tendo em mente a acessibilidade, precisão e rapidez no atendimento: seria um ambiente onde as pessoas, em um só lugar, poderiam receber informações filtradas e precisas para as suas perguntas. As seções da BPE e as instituições públicas e privadas que atuam nas áreas de educação, saúde, cidadania, cultura e lazer seriam as lojas do shopping e o balcão de informação corresponderia ao SIC.

A Figura 2 é um esboço de contextualização desse cenário.

\subsection{Produtos}

SIC:

Resultariam da implantação de um

a) arquivos de informação especializados sobre políticas públicas e nas áreas abrangidas pelas informações solicitadas ao Serviço;

b) cadastro de entidades públicas e privadas que atuam nas áreas social, cultural, educacional, de cidadania, saúde e lazer;

c) páginas no site da BPE para divulgação de oportunidades e atividades que melhorem a qualidade de vida de sua clientela; e

d) uma agenda de atividades educativas, culturais e de entretenimento gratuitas ou a preço módico, também disponível no site da Biblioteca.

Esses produtos seriam atualizados, periodicamente, de acordo com a especificidade e demanda. Dessa forma, levaria à constituição de redes e interações sociais, tendo como enfoque a informação utilitária. Esse é um assunto bem explanado na tese de Maria Cristina Guimarães Oliveira, professora da Universidade Federal de Pernambuco (UFPE), que aborda também questões voltadas às de comunicação, informação, redes e políticas sociais inseridas no bairro de Santo Amaro, em Recife (PE). A autora afirma que relacionados ao conceito de capital social "estão implícitos: educação, saúde, direitos sociais e informação como conquistas capazes de enriquecer o tecido social". (OLIVEIRA, 2007, p. 47). Defende que

\section{O ponto de partida para a formulação de uma nova abordagem considera a disseminação e o acesso à informação como essenciais ao crescimento da so- ciedade". (OLIVEIRA, 2007, p. 83).}

Assim, o SIC:

\begin{abstract}
Necessita coletar, controlar, armazenar, recuperar e disseminar informação. A publicidade quanto à sua implantação estimula a participação dos membros da comunidade como fornecedores de informação, contribuindo assim para que, através da divulgação, o serviço se torne conhecido e seja usado pela comunidade, já que, em atividades culturais, a oferta geralmente cria a demanda. (BIBLIOTECA..., 2000, p. 99).
\end{abstract}

A criação de um SIC na BPE depende de aprovação da alta administração. Considera-se que não representa um aumento significativo de recursos financeiros orçamentários por ser possível utilizar, em sua implantação, a infraestrutura existente. Esta proposta sofrerá alterações para se adequar à realidade da Unidade de Assistência ao Usuário e Coleções Especiais, suas funções estarão atreladas às dos setores de Referência e Praça da Informação. É imprescindível levar em conta as condições favoráveis para a existência desse serviço, uma vez que a BPE encontra-se localizada em uma região considerada como um polo educacional e cultural, pois, além das comunidades adjacentes, existem escolas, universidades, igrejas, cinemas, teatros e museus em um raio muito próximo; além disso, é comum a rotina da Biblioteca acolher usuários em período integral, ou seja, são pessoas que passam o dia na Biblioteca, circulando pelos diversos setores de atendimento ao público, muitos em busca de informações específicas, outros à procura de novidades, e alguns, simplesmente, em busca de um passatempo.

\section{CONSIDERAÇÕES FINAIS}

É importante salientar que a BPE, além de suas funções básicas, promotora da 
educação, cultura e lazer, serve também de apoio às bibliotecas escolares da Região Metropolitana do Recife, doando-lhes documentos e atendendo a estudantes das escolas que não dispõem de bibliotecas nem de acervos atualizados. Observando a sua trajetória percebe-se que, "tirando leite de pedras", está sempre oferecendo novos serviços aos usuários, é para a sociedade como um templo de informação, ao disponibilizar serviços úteis à comunidade local.

O uso da tecnologia da informação tem contribuído para o desenvolvimento dos serviços oferecidos pela BPE, e é diante desse cenário de novas perspectivas que $\mathrm{o}$ SIC surge como um novo desafio. Ao mesmo tempo, representa uma nova oportunidade. Será uma porta para auxiliar na solução de algumas inquietudes e atender a anseios do cidadão, constituirá mais um elemento do ciclo informacional.
Para a formação de um trinômio da informação com serviços ora oferecidos pela BPE, através da Seção de Assistência ao Usuário (Referência) e da Praça da Informação, julga-se necessária a criação de um espaço direcionado à oferta de informações úteis para a comunidade. Pois, em alguns casos, quando o usuário se dirige à biblioteca, está à procura de uma informação para solucionar problema de ordem pessoal, que lhe proporcione benefícios e melhoria da qualidade de sua vida.

A criação do SIC na BPE, obviamente, fomentaria o uso da Biblioteca e incrementaria o papel de promotora da leitura e centro de educação, informação, cultura, lazer e cidadania. Aumentaria sua interação com outras instituições e órgãos que visam impulsionar os caminhos da cidadania. Ampliaria sua atuação como agente social de mudança.

\title{
PUBLIC LIBRARIES: \\ Proposal for a community information service
}

\begin{abstract}
We propose to establish a community information service (SIC) at the Public Library of the State of Pernambuco (BPE). In this paper we highlight the public library's basic functions, as well as how they evolved in response to social, political, educational, and technological changes. We focus on SIC/BPE's needs, as well as the services' purpose, objectives, and administrative aspects (e.g. hours of operation, staff, location, material resources and relations with other sectors of BPE). Information products that generate value-added are pointed out. This proposal aims to contribute to the implementation of the service in other public libraries in Brazil given availability of resources.
\end{abstract}

Keywords

Public Library. Community information service. Utilitarian information.

Artigo recebido em 19/08/2018 e aceito para publicação em 02/10/2018

\section{REFERÊNCIAS}

ABATH, R. J. et al. Experiência de serviços informacionais para comunidades economicamente desfavorecidas na cidade de João Pessoa - PB. Informação \& Sociedade: Estudos, João Pessoa, v. 6, n. 1, p. 45-56, 1996.

ALMEIDA JÚNIOR, O. F. Bibliotecas alternativas. In: ALMEIDA JÚNIOR, O. F. Bibliotecas públicas e bibliotecas alternativas. Londrina: UEL, 1997. p. 63-89.
BERNARDINO, M. C. R.; SUAIDEN, E. J. O papel social da biblioteca pública na interação entre informação e conhecimento no contexto da ciência da informação. Perspectivas em Ciência da Informação, Belo Horizonte, v. 16, n. 4, p.29-41, out./dez. 2011. Disponível em: http://portaldeperiodicos.eci.ufmg.br/index .php/pci/article/view/1257/970. Acesso em: 27 maio 2018. 
BIBLIOTECA pública: princípios e diretrizes. Rio de Janeiro: Fundação Biblioteca Nacional, 2000.

CORREIA, Z. P. A biblioteca pública como espaço de cidadania. In: CALIXTO, J. A. Biblioteca para a vida. Évora, Portugal: Publicações do Cidehus, Edições Colibri, Biblioteca Pública de Évora, 2005. p. 51-65. Disponível em:

https://books.openedition.org/cidehus/175 0. Acesso em: 27 maio 2018.

COSTA, I. D. P. O serviço de informação à comunidade nas bibliotecas públicas portuguesas. In CONGRESSO NACIONAL DE BIBLIOTECÁRIOS, ARQUIVISTAS E DOCUMENTALISTAS, 8., 2004, Estoril, Portugal. Actas... Estoril: BAD, 2004. Disponível em: https://www.bad.pt/publicacoes/index.php /congressosbad/article/view/639/636. Acesso em: 28 jan. 2018.

COSTA, M. N. M. et al. Biblioteca pública como centro de informação utilitária: uma experiência no município de Santa Rita - PB: relatório de pesquisa - 1a. etapa, Revista da Escola de Biblioteconomia da UFMG, Belo Horizonte, v. 13, n. 2, p. 179-195, set. 1984.

DUCKWORTH, A. M. et al. Biblioteca pública e comunidades: prestação de serviço de utilidade pública. In: CONGRESSO BRASILEIRO DE BIBLIOTECONOMIA E DOCUMENTAÇÃO, 16., 1991, Salvador. Anais... Salvador, APBEB, 1991.

FIGUEIREDO, N. Inovação, produtividade e sistemas de informação. Ciência da Informação, Brasília, v. 18, n. 1, p. 83-95, jan./jun. 1989.

FIGUEIREDO, N. Serviço de informação para a comunidade como um instrumento de democratização da biblioteca pública brasileira. Revista Brasileira de Biblioteconomia e Documentação, São Paulo, v. 18, n. 3/4, p. 7-10, dez. 1985.
GLÉRIA, C. R. Z.; ALVES FILHO, N. PSIU - Projeto de Serviços e Informações Utilitárias: relato de uma experiência na Biblioteca Pública Municipal de Londrina (PR). Informação \& Informação, Londrina, v. 5, n. 2, p. 125-137, jul./dez. 2000. Disponível em: http://www.uel.br/revistas/uel/index.php/i nformacao/article/view/1668/1420.

Acesso em: 06 fev. 2018.

MANIFESTO da IFLA/UNESCO sobre bibliotecas públicas: 1994. Disponível em: https://www.ifla.org/files/assets/publiclibraries/publications/PL-manifesto/plmanifesto-pt.pdf. Acesso em: 26 jan. 2018.

MILANESI, L. Centro de ação cultural. In: MILANESI, L. Centro de cultura: forma e função. São Paulo: Hucitec, 1990. p. 71-82.

OLIVEIRA, M. C. G. O uso social da informação na rede de desenvolvimento de Santo Amaro. Recife: A Autora, 2007.

ORTEGA, C. D. Relações históricas entre Biblioteconomia, Documentação e Ciência da Informação. DataGramaZero - Revista de Ciência da Informação, v. 5, n. 5, out. 2004. Disponível em: http://www.brapci.inf.br/index.php/article /view/0000002048/e908b9a74b0fb8f5aff3b d1881eec6b2/. Acesso em: 06 jan. 2018.

PERNAMBUCO. Lei n ${ }^{\circ}$ 12.435, de 06 de outubro de 2003. Dispõe sobre a remessa, o depósito legal e a guarda de obras culturais à Biblioteca Pública do Estado de Pernambuco. Diário Oficial do Estado de Pernambuco, Poder Legislativo, Recife, 07 out. 2003. Disponível em: http://200.238.101.22/docreader/docreader .aspx?bib=DO_200310\&pasta $=$ Dia $\% 2006$. Acesso em: 10 ago. 2018.

PERNAMBUCO. Secretaria de Educação. Biblioteca Pública do Estado de Pernambuco. 2018. Disponível em: http://www.biblioteca.pe.gov.br/. Acesso em: 10 ago. 2018. 
SISTEMA NACIONAL DE BIBLIOTECAS PÚBLICAS. Dados das bibliotecas públicas no Brasil. 2015. Disponível em: http://snbp.culturadigital.br/informacao/da dos-das-bibliotecas-publicas/. Acesso em: 17 abr. 2018.

SUAIDEN, E. J. Biblioteca pública e informação à comunidade. São Paulo: Global, 1995.

USHERWOOD, B. Community information In: EVANS, Margaret Kinnell (Ed.). Informing communities: the role of libraries and information services. London: Community Services Group of Library Association, 1992. p. 17-39.

VERRI, G. M. W. Templários da ausência em bibliotecas populares. Recife: Ed. Universitária, 1996.

ZAHER, C. R. Prefácio. In: BIBLIOTECA pública: princípios e diretrizes. Rio de Janeiro: Fundação Biblioteca Nacional, 2000.

\section{ANEXO - MANIFESTO DA UNESCO - 1994 IFLA/UNESCO}

Public Library Manifesto 1994

MANIFESTO DA IFLA/UNESCO SOBRE BIBLIOTECAS PÚBLICAS 1994

A liberdade, a prosperidade e o desenvolvimento da sociedade e dos indivíduos são valores humanos fundamentais. Só serão atingidos quando os cidadãos estiverem na posse da informação que lhes permita exercer os seus direitos democráticos e ter um papel activo na sociedade. A participação construtiva e o desenvolvimento da democracia dependem tanto de uma educação satisfatória, como de um acesso livre e sem limites ao conhecimento, ao pensamento, à cultura e à informação.

A biblioteca pública - porta de acesso local ao conhecimento - fornece as condições básicas para uma aprendizagem con- tínua, para uma tomada de decisão independente e para o desenvolvimento cultural dos indivíduos e dos grupos sociais.

Este Manifesto proclama a confiança que a UNESCO deposita na Biblioteca Pública, enquanto força viva para a educação, a cultura e a informação, e como agente essencial para a promoção da paz e do bemestar espiritual nas mentes dos homens e das mulheres.

Assim, a UNESCO encoraja as autoridades nacionais e locais a apoiar activamente e a comprometerem-se no desenvolvimento das bibliotecas públicas.

\section{A Biblioteca Pública}

A biblioteca pública é o centro local de informação, tornando prontamente acessíveis aos seus utilizadores o conhecimento e a informação de todos os géneros.

Os serviços da biblioteca pública devem ser oferecidos com base na igualdade de acesso para todos, sem distinção de idade, raça, sexo, religião, nacionalidade, língua ou condição social. Serviços e materiais específicos devem ser postos à disposição dos utilizadores que, por qualquer razão, não possam usar os serviços e os materiais correntes, como por exemplo: minorias linguísticas, pessoas deficientes, hospitalizadas ou reclusas.

Todos os grupos etários devem encontrar documentos adequados às suas necessidades. As colecções e serviços devem incluir todos os tipos de suporte e tecnologias modernas apropriados, assim como fundos tradicionais. É essencial que sejam de elevada qualidade e adequadas às necessidades e condições locais. As colecções devem reflectir as tendências actuais e a evolução da sociedade, bem como a memória da humanidade e o produto da sua imaginação.

As colecções e os serviços devem ser isentos de qualquer forma de censura ideológica, política ou religiosa e de pressões comerciais. 